\title{
Psychometric properties of the Impact of Event Scale-6 in a sample of victims of bank robbery
}

This article was published in the following Dove Press journal:

Psychology Research and Behavior Management

I April 2015

Number of times this article has been viewed

\section{Gabriele Giorgi' \\ Francisco Saverio Fiz Perez' \\ Andrea Castiello \\ D'Antonio' \\ Nicola Mucci² \\ Claudia Ferrero 3 \\ Vincenzo Cupelli ${ }^{3}$ \\ Giulio Arcangeli ${ }^{3}$}

'Department of Psychology, European University, Rome, Italy; ${ }^{2}$ Occupational Medicine Unit, Department of Public Health, Catholic University of the Sacred Heart, Rome, Italy; ${ }^{3}$ Health Services Research Unit, Department of Experimental and Clinical Medicine, University of Florence, Florence, Italy

\section{Video abstract}

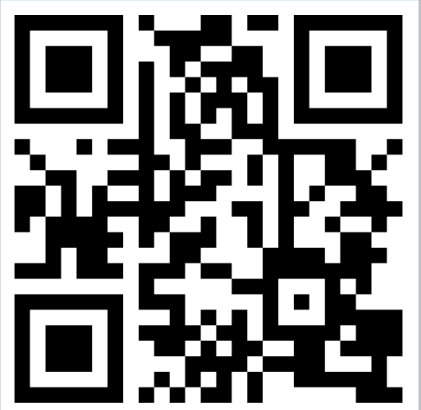

Point your SmartPhone at the code above. If you have a QR code reader the video abstract will appear. Or use: http://dvpr.es/ltuqz81

Correspondence: Gabriele Giorgi Department of Psychology and Human Sciences, European University of Rome, 190 Via degli Aldobrandeschi, I-00163 Rome, Italy

Tel +3906 66543912

Fax +390666543814

Email gabriele.giorgi@unier.it
Abstract: Bank robberies are becoming a serious problem in Italy. This study aims to evaluate the validity and the reliability of the Italian version of Impact of Event Scale (IES)-6. It is also hypothesized that a potential posttraumatic disorder, as measured by the IES-6, is associated with mental health problems and several peritraumatic variables. A database was built from data collected through a survey of victims of robbery in an Italian bank. The final sample comprised 350 employees. This study tests different models of IES, comparing the validity of IES-6 with the 22 -item original version (IES-R) and the 15 -item Italian version (recently adopted in a sample of flood victims). A confirmatory factor analysis supported the IES-6 three-factor solution as the best model. In addition, the internal consistency of the IES- 6 and the subscales was good. Outcomes revealed a robust structure supporting the composition of the IES-6 Italian version. Keywords: bank robbery, employees, posttraumatic, peritraumatic, Impact of Event Scale, questionnaire

\section{Introduction}

A recent review of Van den Bossche et $\mathrm{al}^{1}$ has shown that violence at work is increasing in Europe. In terms of violence in Italy, a serious concern is represented by bank robberies.

Although international and national legislations have been introduced to protect employees from workplace violence, the problem is still a major threat. ${ }^{2,3}$ Data on the frequency of exposure to bank robbery strongly support this view. In Italy, in 2013, robberies increased by $7.5 \%{ }^{4}$ Accordingly, the prevalence of bank robberies is extremely high in Italy, especially in comparison with other countries. ${ }^{4}$ As shown by Mastrobuoni, ${ }^{5}$ the prevalence of bank robberies in Italy is higher than in the rest of Europe combined.

Targets of robbery can be severely traumatized, by both the potential and the actual violence, stimulating the development of mental health problems and posttraumatic stress disorder (PTSD). PTSD is a response to a particularly stressful event or situation (either brief or extended) which is likely to cause anyone distress. Indeed, PTSD impacts negatively on physical and mental health and increases the demand on medical services. ${ }^{6}$ A traumatic event is a necessary PTSD diagnostic criterion, according to the Diagnostic and Statistical Manual of Mental Disorders (DSM)-IV and DSM-5, as are the generation of specific symptoms such as intrusion (intrusive thoughts, nightmares, intrusive feelings and imagery, and dissociative-like reexperiencing), avoidance (numbing of responsiveness, avoidance of feelings, situations, and ideas), and hyperarousal (anger, irritability, hypervigilance, difficulty concentrating, and heightened alarm). 
In addition, among victims of bank robberies, symptoms of posttraumatic stress and mental health problems seem to manifest immediately following the robbery and earlier than other workplace trauma. ${ }^{7}$ Despite the frequency and the severe psychological effects of workplace robberies, little empirical research has examined PTSD in bank robberies in Italy. This study seeks to verify the validity and the reliability of a shorter version of the Impact of Event Scale (IES-6) ${ }^{8}$ in a population of Italian bankers.

\section{The impact of event scale}

IES has a worldwide reputation in measuring various traumatic experiences in different samples and seems to be very effective, both for epidemiology and intervention purposes. Although not immune to criticism for not strictly following the diagnostic criteria of DSM-IV and DSM-5, it was found to be very valuable as a screening instrument for PTSD. ${ }^{9,10}$

Initially, IES was based on observations of the traumatic life events that generated serious psychological symptoms. ${ }^{11}$ Later, a revised version (IES-R) was developed in order to include a scale measuring hyperarousal, ${ }^{12}$ one of the central features of PTSD in DSM-IV.

Indeed, the IES-R (22-item) includes seven additional items tailored to measure the hyperarousal symptoms of PTSD, which were not contained in the original IES.

In Italy, a new version of the IES-R was adapted. ${ }^{13}$ This new Italian version has 15 questions and appears to be a good and parsimonious instrument. Seven items were deleted from the original version, for example, item 2, "I had trouble staying asleep"; item 4, "I felt irritable and angry"; item 5, "I avoided letting myself get upset when I thought about it or was reminded of it." Although this adaptation is recent and well conducted, international literature is converging on a shorter version of the scale. In the study by Thoresen et al, ${ }^{8}$ the IES-R has been shortened. Although this scale (called IES-6) contains only six items, the correlations with the IES-R across samples were high (pooled correlation $=0.95$ ). In addition, this shorter instrument measures the principal aspects of posttraumatic stress identified by the literature.

IES-6 seems particularly useful for screening individuals with significant traumatic stress symptoms as the first step of a further assessment to determine whether they fulfill the entire criteria for a diagnosis of PTSD. ${ }^{8}$ This study focuses mostly on the psychometric properties of IES-R-6, because it seems necessary for scientists and practitioners to have instruments that can be quickly administered, ${ }^{14}$ especially in the bank robberies field where employees seem to be the subject of survey earlier than victims of trauma in other populations.

In doing so, we also wish to investigate IES-6 convergent validity. Several studies have confirmed the strong association of IES with poor mental health and psychological problems such as depression and anxiety; ${ }^{15-17}$ however, very little research has been conducted in the Italian context. ${ }^{13}$

In addition, peritraumatic risk factors have also been investigated in association with IES. These risk factors are those closely related to the event: duration, intensity, and nature of the traumatic event. Literature found a strong association between perceived life threat and posttraumatic symptoms, both in victims of robberies and in victims of other types of assault and aggression. ${ }^{18}$ For instance, believing they, or someone else, could be harmed, feeling threatened by the robber, or seeing a weapon might increase the risk of developing PTSD. ${ }^{6,15}$ In addition, literature found a relationship between PTSD and perceived helplessness, since traumatized employees seem to commonly feel helpless or fearful during the robbery. ${ }^{6,15}$

Since the IES scores appear to be linked with peritraumatic factors, these associations might be important for validity testing.

\section{Aim}

The main aim of this paper was to test the factor structure of the IES-6 Italian version, conducting a first-order confirmatory factor analysis (CFA) using a dataset consisting of victims of bank robberies.

Using an alternative models approach, this study set out to test three models, which were based on the results of previous validation studies of IES versions.

The three tested models were the original 22-item, ${ }^{12}$ the 15-item, ${ }^{13}$ and the 6 -item. ${ }^{8}$ We hypothesized that the 6 -item Italian version would show the best fit. In addition, we expected that the IES-6 would be strongly associated with the IES-R Italian version and the 22-item version, as well as with the General Health Questionnaire (GHQ-12). Finally, the associations of the IES-6 subscores with peritrauma variables were investigated.

\section{Method}

\section{Participants}

The sample consisted of 350 employees across Italy. All the organizations where a robbery took place belonged to a national Italian bank, which agreed to have researchers administer the survey on site. The survey, which was administered 1-7 days after the robberies, not only had research 
purposes, but was also aimed to fulfill the obligations on work-related stress, as amended by the Italian Legislative Decree No 81/2008 and subsequent amendments. ${ }^{19,20}$ The choice of the administration time frame followed previous studies conducted among victims of bank robberies. ${ }^{15,21}$ Most of the victims of armed robbery seem to have clinically significant symptoms of posttraumatic stress immediately following the robbery. ${ }^{21}$

The survey comprised a total of $202(57.7 \%)$ males and 148 $(42.3 \%)$ females, and the mean age was $40.8( \pm 10.1)$ years.

\section{Questionnaire}

The questionnaire was composed of three sections. The first section asked for a short description of the incident. In addition, demographic questions (sex and age) were also included.

The second section requested subjects to specify Yes or No:

1. Whether he/she was involved directly in the robbery

2. Whether he or she felt threatened by the robber

3. Whether he or she imagined himself or herself to potentially be harmed

4. Whether he or she felt great fear

5. Whether he or she had physical contact with the robber. The third part consisted of the following scales:

The Italian version of the GHQ-12.22 This questionnaire measures whether the respondent has recently experienced any particular symptom of mental distress. Six of the items are positive; the other six are negative. After recoding the negative items, a 4-point Likert-scale scoring method was used according to the response alternatives presented to participants $(0=$ "less than usual"; $1=$ "no more than usual"; $2=$ "rather more than usual"; and $3=$ "much more than usual"). Thus, the questionnaire gives a total score ranging from 0 to 36 points, in which a higher score indicates mental health problems. ${ }^{23}$

The IES Revised. ${ }^{12}$ The IES-R is a 22-item self-report measure of psychological distress in response to a specific traumatic event. It includes three subscales that describe the three major symptoms of posttraumatic stress found in the literature: intrusion, avoidance, and hyperarousal. The respondents of the questionnaire are invited to indicate, on a 4-point scale ranging from never (score 0 ) to often (score 4), how frequently each symptom was experienced in the past week.

\section{Analyses}

In order to examine the dimensionality of the IES-R, a confirmatory approach using AMOS 19.0 statistical software was conducted. CFA allows models to be driven both statistically and theoretically, something which traditional procedures such as exploratory factor analysis are unable to do. Maximum likelihood estimation, as recommended by Hoyle and Panter, ${ }^{23}$ was applied. Indeed, the IES-6 model was previously identified and correctly specified; consequently, maximum likelihood parameter estimates were considered consistent. In addition, the goodness of fit for each model was assessed with a range of fit indices.

On the basis of theoretical notions and previous empirical studies, we expected the three underlying factors of PTSD to exist. However, one-dimensional measurement models were also tested for comparison purposes. In the single-factor models, the measurement error terms were uncorrelated. Threefactor models specified correlated factors, with items loading on three factors: avoidance, intrusion, and hyperarousal.

\section{Fit indices}

Maximum likelihood estimates were calculated using the covariance matrix of the items. The following indices were computed: 1) the root mean square error of approximation (RMSEA), 2) the goodness of fit index (GFI), 3) the adjusted goodness of fit index (AGFI), 4) the comparative fit index (CFI), 5) the incremental fit index (IFI), and 6) the root mean squared residual (RMR). The RMSEA is a measure of the discrepancy per degree of freedom for the model. Values smaller than 0.08 are indicative of an acceptable fit. ${ }^{24}$ RMR is an absolute misfit index. RMR values smaller than 0.08 indicate an acceptable fit. The GFI is a measure of the relative amount of variance accounted for by the model, whereas the AGFI also takes model parsimony into account. ${ }^{25}$ The computation of indices with values above 0.95 is strongly recommended. ${ }^{26,27}$ The CFI (as well as the IFI) is a population measure of model misspecification that is recommended for model comparison purposes. ${ }^{28}$ Values greater than 0.95 are basically considered as indicating a good fit. ${ }^{29}$

\section{Additional analysis}

In order to investigate the extent to which IES-6 factors were correlated with each other and with the general health, we used the Pearson correlation coefficient. A $t$-test was performed to assess the associations of peritrauma variables (our independent variables) with the three IES-6 subscales (our dependent variables).

Finally, as far as the reliability of the questionnaire is concerned, internal consistencies of the scale and subscales were calculated using Cronbach's $\alpha$ coefficient. In addition, for the total scale, split-half reliability was calculated. In conclusion, item scale correlations were examined for each 
Table I Confirmatory factor analysis for the IES-R $(n=350)$

\begin{tabular}{lllllllll}
\hline & $\chi^{2}$ & df & GFI & CFI & RMSEA & AGFI & IFI & RMR \\
\hline $\begin{array}{l}\text { One-factor } \\
\text { IES-R-22 }\end{array}$ & 818 & 209 & 0.81 & 0.87 & 0.09 & 0.77 & 0.87 & 0.09 \\
$\begin{array}{l}\text { One-factor } \\
\text { IES-R-I5 }\end{array}$ & 306 & 90 & 0.88 & 0.92 & 0.09 & 0.84 & 0.92 & 0.08 \\
$\begin{array}{l}\text { One-factor } \\
\text { IES-R-6 }\end{array}$ & 37 & 9 & 0.97 & 0.97 & 0.09 & 0.92 & 0.97 & 0.06 \\
$\begin{array}{l}\text { Three-factor } \\
\text { IES-R-22 }\end{array}$ & 658 & 206 & 0.85 & 0.90 & 0.08 & $0.8 \mathrm{I}$ & 0.90 & 0.08 \\
$\begin{array}{l}\text { Three-factor } \\
\text { IES-R-I5 }\end{array}$ & 192 & 87 & 0.93 & 0.96 & 0.06 & 0.91 & 0.96 & 0.06 \\
$\begin{array}{l}\text { Three-factor } \\
\text { IES-R-6 }\end{array}$ & 12 & 6 & 0.99 & 0.99 & 0.05 & 0.96 & 0.99 & 0.04 \\
\hline
\end{tabular}

Abbreviations: IES-R, Impact of Event Scale - Revised; df, degrees of freedom; $\mathrm{GFI}$, goodness of fit index; CFI, comparative fit index; RMSEA, root mean square error of approximation; AGFI, adjusted goodness of fit index; IFI, incremental fit index; RMR, root mean squared residual.

of the instrument subscales, ensuring that item-total correlations exceeded the value of 0.30 , which is recommended for testing the internal consistency of a scale.

\section{Results}

\section{Validity and reliability}

To test the validity of the IES, we followed a confirmatory approach with two distinguishable measurement models. These were one-dimensional models with all items measuring the same latent variable and three-dimensional models with items loading exclusively on each posttraumatic factor.
In addition, we considered the fit of the IES- 6 by comparing those obtained by the IES-15 and IES-22 versions. The analysis showed that an overall posttraumatic stress measure (one dimension) does not fit well to the data, whereas the three-dimensional solution is associated with acceptable descriptive fit indices. Data showed a better fit for the 6 -item version (Table 1), whereas the 22-item version does not seem valid and the 15 -item version seems acceptable; the 6-item version presents good validity with all fit indices, also respecting more stringent validity criteria. In addition, the standardized factor loadings for the IES-6 three-factor model were all statistically significant $(P<0.001)$ and ranged from 0.72 to 0.84 (Figure 1).

We assessed convergent validity by comparing scores on the IES-6 scale with a validated measure of a similar construct, such as mental health disorder.

There was a positive correlation of IES-6 with GHQ-12, indicating that the more traumatized a person is, the more they are inclined to report mental health problems. In addition, the three dimensions of posttraumatic stress were strongly correlated, and as expected, IES-6 was strongly correlated with the 15-item Italian version and with the 22 -item original version.

Furthermore, the item-total correlations within each subscale were all above 0.40 , indicating satisfactory associations between items and their scales.

Finally, Cronbach's $\alpha$ for the 6-item version in the posttraumatic scale was 0.88 , indicating a very good internal

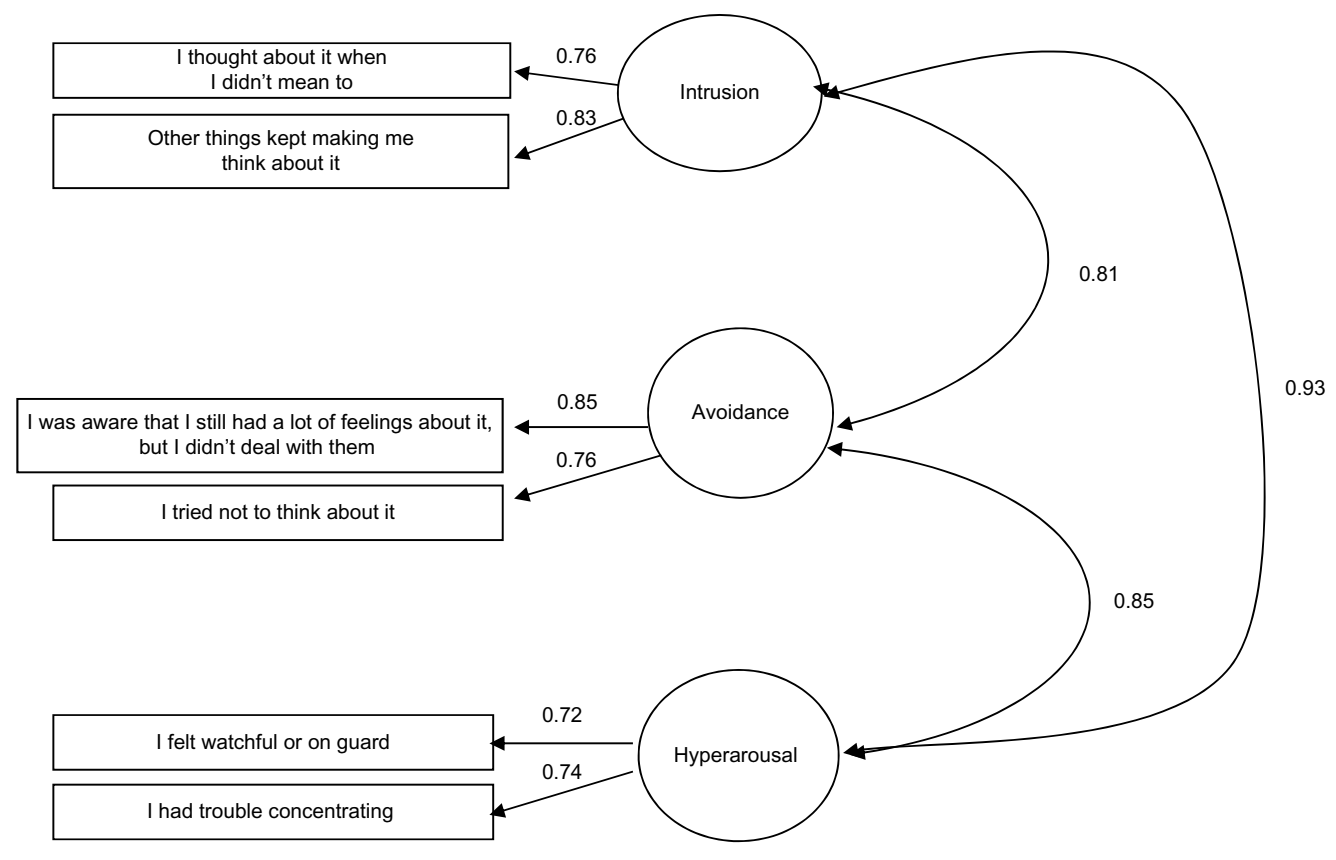

Figure I Confirmatory factor analysis for the IES-R ( $n=350)$.

Abbreviation: IES-R, Impact of Event Scale - Revised. 
Table 2 Means, standard deviations, alpha, and correlations among variables

\begin{tabular}{|c|c|c|c|c|c|c|c|c|c|c|c|c|}
\hline \multirow[t]{2}{*}{ Variables } & \multirow[t]{2}{*}{$M$} & \multirow[t]{2}{*}{ SD } & \multirow[t]{2}{*}{ Alpha } & \multicolumn{9}{|c|}{ Variables } \\
\hline & & & & $\mathbf{I}$ & 2 & 3 & 4 & 5 & 6 & 7 & 8 & 9 \\
\hline I. Arousal IES-6 & 2.7 & 2.3 & 0.78 & - & $0.62 * *$ & $0.73 * *$ & $0.89 * *$ & $0.87 * *$ & $0.84 * *$ & $0.68 * *$ & -0.04 & 0.00 \\
\hline 2. Avoidance IES-6 & 2.6 & 2.2 & 0.69 & & - & $0.60 * *$ & $0.86 * *$ & $0.78 * *$ & $0.80 * *$ & $0.47^{* *}$ & -0.05 & -0.03 \\
\hline 3. Intrusion IES-6 & 3.0 & 2.4 & 0.78 & & & - & $0.74 * *$ & $0.85 * *$ & $0.86 * *$ & $0.57^{* *}$ & -0.08 & -0.02 \\
\hline 4. IES-6 total scale & 7.7 & 6.3 & 0.88 & & & & - & $0.94 * *$ & $0.93 * *$ & $0.67 * *$ & -0.06 & -0.03 \\
\hline 5. IES-22 total scale & 28.9 & 20.5 & 0.95 & & & & & - & $0.99 * *$ & $0.70 * *$ & -0.07 & -0.05 \\
\hline 6. IES-I5 total scale & 19.9 & 14.0 & 0.93 & & & & & & - & $0.68 * *$ & -0.03 & -0.03 \\
\hline 7. GHQ total scale & 11.2 & 5.4 & 0.83 & & & & & & & - & -0.03 & -0.03 \\
\hline 8. Sex & $\mathrm{I} .4$ & 0.49 & - & & & & & & & & - & $-0.30^{* *}$ \\
\hline 9. Age & 40.8 & 10.1 & - & & & & & & & & & - \\
\hline
\end{tabular}

Note: ${ }^{* *}$ Correlation is significant at the 0.01 level (two-tailed).

Abbreviations: SD, standard deviation; IES, Impact of Event Scale; GHQ, General Health Questionnaire.

consistency (Table 2). Split-half reliability was also satisfactory, with a Spearman-Brown coefficient of 0.85. In addition, the posttraumatic dimensions also presented acceptable internal reliability, with the calculation of the Cronbach's $\alpha$ showing 0.69 for avoidance, 0.78 for arousal, and 0.78 for intrusion.

\section{Additional psychometric analyses}

Further criterion-related validity was based on hypothesized associations of IES-6 with peritrauma variables. To analyze whether posttraumatic stress factors were associated with participants' peritrauma experiences, several $t$-tests were performed. For those involved directly in the robbery, victims scored significantly higher than observers in avoidance ( $t=4.37, d f=343, P<0.001)$, in intrusion $(t=4.57, d f=343$, $P<0.001)$, and in arousal $(t=3.15, d f=343, P<0.001)$.

Similarly, if workers felt threatened by the robber, they seemed to develop more serious posttraumatic symptoms: avoidance $(t=4.67, d f=347, P<0.001)$, intrusion $(t=5.90$, $d f=347, P<0.001)$, and arousal $(t=5.15, d f=347, P<0.001)$. As expected, employees who imagined they might be harmed (avoidance: $t=5.0, d f=347, P<0.001$; intrusion: $t=7.54$, $d f=347, P<0.001$; arousal: $t=6.10, d f=347, P<0.001$ ) or felt fearful during the robbery (avoidance: $t=8.60, d f=347$, $P<0.001$; intrusion: $t=8.34, d f=347, P<0.001$; arousal: $t=9.37, d f=347, P<0.001)$ developed more posttraumatic symptoms.

Finally, those having reported physical contact with the robber seem to be associated with higher scores in the IES-6 (avoidance: $t=3.13, d f=347, P<0.001$; intrusion: $t=3.31$, $d f=347, P<0.01$; arousal: $t=2.49, d f=347, P<0.05$ ).

\section{Discussion and conclusion}

This study points out that the 6-item IES is a statistically valid measure of posttraumatic stress. CFA confirmed that the three-factor model represents the construct well. The confirmatory factor analysis showed that a three-factor structure of the scale yields a better fit than a one-factor structure. The fit of the model was satisfactory and better than those obtained by both the 15 - and the 22 -item versions. In addition, both posttraumatic factors, as well as the entire scale, seemed to be reliable. As far as convergent validity is concerned, the scale behaved as expected, because it was related to a similar construct (mental health disorder) and significantly related to hypothesized peritrauma variables. Indeed, both the total score and the three dimensions of the IES- 6 were also found to be positively correlated with general health. Similarly, the associations of the IES-6 with peritrauma variables generally tended to be consistent with previous findings in this area.

Surprisingly, sex was not correlated with IES-R. This result follows a meta-analytic study in which sex had a limited association with PTSD. ${ }^{30}$

Finally, IES-6 correlated strongly with longer versions of the instrument. The potential of using a short instrument for PTSD, such as the IES-6 assessment, seems significant. PTSD measures might contain a number of items which are less specific to PTSD. ${ }^{14}$ If these items are superfluous, a shorter version of the instrument would better screen PTSD "at risk" individuals.

Although our study has a number of strengths, it is not without limitations. First, we point out that the cross-sectional nature of the study does not allow for confirming the stability of the scale across time, and consequently, longitudinal studies are also needed for test-retest purposes. Indeed, our study was focused primarily on IES-6 construct validity using CFA. In addition, further validation studies are required in different samples of employees. Second, the questionnaire was administered 1 week postrobbery. Although this time frame was used in previous research, according to DSM-IV and DSM-5, the reactions in the first 48 hours (DSM-IV) 
and the first 72 hours (DSM-5) are normal transient ones and cannot be regarded as pathological posttraumatic stress reactions. Third, we administered the 22-item IES-R, from which we validated the 6 -item version. This procedure limits the face validity of our study. However, we conclude that the IES-6 reported satisfactory reliability and validity. In addition, it can measure posttraumatic stress very accurately and fast. Indeed, one of the main strengths of this revised instrument is that it is short, easy to administer, and could also be used for longitudinal studies. Empirically, support has also been provided in this study for the distinction between intrusion, avoidance, and arousal in the aftermath of bank robbery, and therefore, we suggest using these different experiences of posttraumatic stress for research and intervention purposes.

\section{Disclosure}

The authors report no conflicts of interest in this work.

\section{References}

1. Van den Bossche S, Taris T, Houtman I, Smulders P, Kompier M. Workplace violence and the changing nature of work in Europe: trends and risk groups. Eur J Work Organ Psychol. 2013;22(5):588-600.

2. Chappell D, Di Martino V. Violence at Work. 3rd ed. Geneva, Switzerland: International Labour Organization; 2006.

3. Giorgi G, Arcangeli G, Mucci N, Cupelli V. Economic stress in workplace: the impact of fear the crisis on mental health. Work. Epub March 4, 2014. doi:10.3233/WOR-141844.

4. Tabanelli MC, Bonfiglioli R, Violante FS. Bank robberies: a psychological protocol of intervention in financial institutions and principal effects. Work. Epub March 26, 2014.

5. Mastrobuoni G. Everybody Stay Cool, this is a Robbery [article on the Internet]. 2009. Available from: http://citeseerx.ist.psu.edu/viewdoc/ summary? doi=10.1.1.212.3844. Accessed September 3, 2014.

6. Hansen M, Elklit A. Predictors of acute stress disorder in response to bank robbery. Eur J Psychotraumatol. 2011;2. doi:10.3402/ejpt. v2i0.5864.

7. Richards D. Symptom severity, personal and social variables after armed robbery. Br J Clin Psychol. 2000;39(Pt 4):415-419.

8. Thoresen S, Tambs K, Hussain A, Heir T, Johansen VA, Bisson JI. Brief measure of posttraumatic stress reactions: Impact of Event Scale-6. Soc Psychiat Epidemiol. 2010;45:405-412.

9. Wohlfarth TD, van den Brink W, Winkel FW, Ter Smitten M. Screening for posttraumatic stress disorder: an evaluation of two self-report scales among crime victims. Psychol Assess. 2003;15:101-109.

10. Brewin CR. Systematic review of screening instruments for adults at risk of PTSD. J Trauma Stress. 2005;18:53-62.

11. Horowitz M, Wilner N, Alvarez W. Impact of Event Scale: a measure of subjective stress. Psychosom Med. 1979;41(3):209-218.

Psychology Research and Behavior Management

\section{Publish your work in this journal}

Psychology Research and Behavior Management is an international, peerreviewed, open access journal focusing on the science of psychology and its application in behavior management to develop improved outcomes in the clinical, educational, sports and business arenas. Specific topics covered include: Neuroscience, memory \& decision making; Behavior
12. Hyer K, Brown LM. The Impact of Event Scale-Revised: a quick measure of a patient's response to trauma. Am J Nurs. 2008;108(11):60-69.

13. Craparo G, Faraci P, Rotondo G, Gori A. The impact of Event Scale revised: psychometric properties of the Italian version in a sample of flood victims. Neuropsychiatr Dis Treat. 2013;9:1427-1432.

14. Hansen M, Andersen TE, Armour C, Elklit A, Palic S, Mackrill T. PTSD-8: a short PTSD inventory. Clin Pract Epidemiol Ment Health. 2010;6:101-108.

15. Hansen M, Elklit A. Does acute stress disorder predict posttraumatic stress disorder following bank robbery? J Interpers Violence. 2013; 28(1):25-44.

16. Lilly MM, Pierce H. PTSD and depressive symptoms in 911 telecommunicators: the role of peritraumatic distress and world assumptions in predicting risk. Psychol Trauma. 2013;5(2):135-141.

17. Rutter LA, Weatherill RP, Krill SC, Orazem R, Taft CT. Posttraumatic stress disorder symptoms, depressive symptoms, exercise, and health in college students. Psychol Trauma. 2013;5(1):56-61.

18. Kleim B, Ehlers A, Glucksman E. Early predictors of chronic posttraumatic stress disorder in assault survivors. Psychol Med. 2007; 37(10): 1457-1467.

19. Giorgi G, Leon-Perez JM, Cupelli V, Mucci N, Arcangeli G. Do I just look stressed or am I stressed? Work-related stress in a sample of Italian employees. Ind Health. 2014;52(1):43-53.

20. Mucci N, Giorgi G, Cupelli V, et al. Work-related stress assessment in a population of Italian workers. The Stress Questionnaire. Sci Total Environ. 2014;502C:673-679. doi:10.1016/j.scitotenv.2014.09.069.

21. Belleville G, Marchand A, St-Hilaire MH, Martin M, Silva C. PTSD and depression following armed robbery: patterns of appearance and impact on absenteeism and use of health care services. JTrauma Stress. 2012;25(4):465-468.

22. Piccinelli M, Bisoffi G, Bon MG, Cunico L, Tansella M. Validity and test-retest reliability of the Italian version of the 12-item General Health Questionnaire in general practice: a comparison between three scoring methods. Compr Psychiatry. 1993;34(3):198-205.

23. Hoyle RH, Panter AT. Writing about structural equation models. In: Hoyle RH, editor. Structural Equation Modeling: Concepts, Issues, and Applications. Thousand Oaks, CA: Sage Publications; 1995: 158-176.

24. Cudeck R, Browne MW. Alternative ways of assessing model fit. In: Bollen KA, Scott Long J, editors. Testing Structural Equation Models. Newbury Park, CA: Sage Publications; 1993:1-9.

25. Jöreskog KG, Sörbom D. LISREL. User's Guide Version VI. 4th ed. Uppsala, Sweden: University of Uppsala; 1986.

26. Bentler P. Fit indexes, Lagrange multipliers, constraint changes and incomplete data in structural models. Multivar Behav Res. 1990;25(2):163-172.

27. Schweizer K. Some guidelines concerning the modeling of traits and abilities in test construction. Eur J Psychol Assess. 2010;26(1):1-2.

28. Goffin RD. A comparison of two new indices for the assessment of fit of structural equation models. Multivar Behav Res. 1993;28(2): 205-214.

29. Hoyle RH. The structural equation modeling approach: basic concepts and fundamental issues. In: Hoyle RH, editor. Structural Equation Modeling, Concepts, Issues and Applications. Thousand Oaks, CA: Sage Publications; 1995:1-15.

30. Sundin EC, Horowitz MJ. Horowitz's impact of Event Scale evaluation of 20 years of use. Psychosom Med. 2003;65(5):870-876.

modification \& management; Clinical applications; Business \& sports performance management; Social and developmental studies; Animal studies. The manuscript management system is completely online and includes a quick and fair peer-review system. Visit http://www.dovepress. com/testimonials.php to read real quotes from published authors. 